\section{Properties of X-Radiation}

THE published accounts of unsuccessful attempts to find the $J$-phenomenon seem to call for some statement of the present position of investigations on the subject. Our experience of the phenomenon is now so extensive, that the comments and suggestions of experimenters are to us of little more than psycho. logical, or shall we say philosophical, interest. Their results represent, at most, an almost negligible number of observations under conditions which we are able to reproduce at any time; they add nothing to our knowledge.

These negative results, that is results showing no $J$-discontinuity, are neither more nor less accurate, neither more nor less real, than those which show the discontinuity. Results of one kind follow laws which are now familiar to physicists; the others are governed by laws which are not as yet generally recognised. It is to the apparent violations of known laws and not to further confirmation under very precise and specialised conditions that we must look for advances in knowledge. The very rigid limitation of the number of variables, usually imposed upon the experimental conditions, is a most effective barrier to discovery in regions which have not been thoroughly explored. These limitations we have tried-indeed experience has taught us-to avoid.

The reality of a $J$-discontinuity can be established by an observer in an hour's time; the wide generality of the phenomenon has however taken months and even years to establish. The laws which govern it have been studied for thousands of working days and certain general conclusions have been reached. How general these laws are, cannot, of course, be told. But they show with certainty that what have previously been regarded as the fundamental laws of $\mathrm{X}$-ray action are not valid; and they introduce us to entirely new conceptions of $\mathrm{X}$-ray phenomena. It is quite evident that not only is the $J$-absorptiondiscontinuity conditional on some unidentified factor but that even the $K$-absorption edge (discovered by us some twenty-five years ago, and now perhaps too faithfully accepted) is conditional, and not perfectly general. In fact, the whole activity of a radiation in a substance is not governed solely by the wave-length of the radiation and the nature of the substance. Confirmation of this statement will be found in the work of Lindh and others on the absorption of X-rays by light substances-work which showed as alternative results absorption lines and absorption edges. It is such alternative results which we have frequently described in association with the $J$-phenomenon.

In this laboratory we have observed the disappearance of the $K$-absorption in a way so pronounced that there is no mistaking it.

It may be that many more years must pass before the results discovered can be attributed to one or two simple measurable quantities. The simplest interpretation has yet to be found. But it is important to know that current theories completely break down - that the quantum (or photon) may become im. potent; that an atmosphere of radiation (not independent quanta or harmonic constituents) is effective; that superposed radiations act as a coherent whole; that, so far as the radiation is concerned, something analogous to temperature of radiation is the dominant factor; that the internal state (and history) of a substance (not simply the nature of constituent atoms) determines its behaviour under X-ray action. How far these conclusions apply to the $K$ and $L$ phenomena has yet to be determined, but even their conditional nature has been established. Detailed accounts will be published in other journals.

University of Edinburgh.

C. G. Barkla. Nov. 18.

\section{Carbonyls of Lithium, Rubidium and Cæsium}

THE carbonyls of certain alkali and alkaline earth metals have been prepared previously by the action of carbon monoxide on a solution of the appropriate metal ammoniate in liquid ammonia. In this way, Joannis $^{1}$ obtained sodium carbonyl, $\mathrm{NaCO}$, and potassium carbonyl, KCO ; Gunz and Mentrel $^{2}$ barium carbonyl, $\mathrm{Ba}(\mathrm{CO})_{2}$ and Roederer ${ }^{3}$ strontium carbonyl, $\mathrm{Sr}(\mathrm{CO})_{2}$. In the course of researches on the carbonyls proceeding in these laboratories, the corresponding compounds of lithium, rubidium and calcium have been obtained.

The carbonyls were prepared by condensing pure, dry ammonia on to a clean specimen of the metal in question by immersing the containing vessel in a bath at $-60^{\circ}$. After complete dissolution, which occupied about 45 minutes, the excess of ammonia was allowed to evaporate, a gentle stream of pure, dry carbon monoxide being meanwhile passed through the apparatus and continued until the metal ammoniate was wholly transformed into the carbonyl. Because of the highly reactive nature of the metals, ammoniates and carbonyls, all the operations were conducted with the rigid exclusion of both air and moisture.

Lithium carbonyl, LiCO, is a white pulverulent substance quantitatively synthesised by these means : found $\mathrm{Li} 18 \cdot 80,19 \cdot 62,21 \cdot 05$ per cent, mean $19 \cdot 82$ per cent; calculated for $\mathrm{LiCO}, 19 \cdot 86$ per cent. It darkens on standing owing presumably to the liberation of minute amounts of carbon, and, on heating in a vacuum, it begins to decompose at $300^{\circ}$ without detonation but with the separation of carbon. At about $500^{\circ}$ this change is completed in a short time, the residue consisting of free carbon, carbonate and oxide, the amount of residual carbon indicating that the reaction takes the course,

$$
4 \mathrm{LiCO}=\mathrm{Li}_{2} \mathrm{CO}_{3}+\mathrm{Li}_{2} \mathrm{O}+3 \mathrm{C} ;
$$

ratio $\mathrm{LiCO} \mathrm{mol} . / \mathrm{C}$ atoms, found $1 \cdot 57$, calculated 1.33 (the high ratio being probably due to the loss of carbon in the colloidal form). When treated with water the carbonyl detonated violently, with instant ignition of the gaseous products, a cloud of soot being produced and a residue of carbonate and carbon left. On the other hand, water vapour was absorbed quietly with the formation of a dirty brown liquid. The carbon from the detonation of the carbonyl gave ratios $\mathrm{LiCO}$ mol./C atoms lying between $2 \cdot 5$ and $3 \cdot 5$. These results together with those of Joannis, who showed that the gas from the detonation of sodium carbonyl with water contained 86 per cent hydrogen and 14 per cent carbon monoxide, indicate the probability of more than one reaction : the high proportion of hydrogen, together with the presence of carbonate in the residue accords well with a reaction of the type,

$$
2 \mathrm{LiCO}+\mathrm{H}_{2} \mathrm{O}=\mathrm{Li}_{2} \mathrm{CO}_{3}+\mathrm{C}+\mathrm{H}_{2}
$$

involving the reduction of water by the carbonyl, which requires $\mathrm{LiCO} / \mathrm{C}=2$.

Rubidium carbonyl is a pure white solid possessing 